\title{
Demand for Long Acting and Permanent Contraceptives Methods and Associated Factors Among Married Women Visiting Assosa Town Health Institution for Family Planning
}

\author{
Zelalem Birku, Semarya Berhe, Yeshi Assefa \\ College of Health Sciences School of Nursing and Midwifery, Addis Ababa University, Addis Ababa, Ethiopia \\ Email address: \\ opbittop@gmail.com (Z. Birku), assefayeshi7@gmail.com (Y. Assefa), semitaye@yahoo.com (S. Berhe) \\ To cite this article: \\ Zelalem Birku, Semarya Berhe, Yeshi Assefa. Demand for Long Acting and Permanent Contraceptives Methods and Associated Factors \\ Among Married Women Visiting Assosa Town Health Institution for Family Planning. Journal of Family Medicine and Health Care. \\ Vol. 7, No. 3, 2021, pp. 65-76. doi: 10.11648/j.jfmhc.20210703.12
}

Received: June 16, 2021; Accepted: July 13, 2021; Published: August 23, 2021

\begin{abstract}
Background: Demand for long acting and permanent contraceptive method is one of the key factors that determine the fertility and the reproductive health of the women. These demand for LAPM was not consistent with and the utilization of LAPM. The objective of this study is therefore, to assess demand for LAPM and associated factors among married women visiting Assosa governmental health institution for family planning service. Method used to conduct the study was, institutional based cross sectional study were conducted to assess demand for LAPM and its associated factor from April 12-May 10/2019 for total of 251 sample size. Data was collected by using pretested structured questionnaire. For the qualitative study, in-depth interview was conducted on purposively selected key informant. Data was analyzed by using SPSS 24 . Th study result indicates, the demand for LAPM at the study area was $158(62.9 \%)$. Awareness about LAPM (AOR=2.503 95\%CI $=1.188-5.2274$ ), knowledge of $\mathrm{LAPM}(\mathrm{AOR}=2.62,95 \% \mathrm{CI}=1.295-5.299)$, previous utilization of $\mathrm{LAPM}(\mathrm{AOR}=3.369,95 \% \mathrm{CI}=1.805-5.291)$ and couple discussion about any LAPM $(\mathrm{AOR}=2.067,95 \% \mathrm{CI}=1.027-4.163)$ were associated with demand for LAPM. Fear of the side effect was the main reason for non-utilization of LAPM. Conclusion: demand for LAPM was not consistent with the utilization. The finding shows that, $62.9 \%$ of the respondent had demand for LAPM. On the basis of the finding, It needs to do more on the limiting factors to utilize LAPM. So the recommendation gos to MOH, RHB, the institution manager together with health care provider and different NGO work more to meet the increasing demand for LAPM.
\end{abstract}

Keywords: Demand for Long Acting, Permanent Contraceptive Methods, Married Women

\section{Introduction}

\subsection{Background}

The health of women is closely related to their reproductive role and pregnancies which are either too early, too close, too many or too late, exposing mothers to high morbidity and mortality at the time of pregnancy and/ during parturition. Family planning one of the key elements of reproductive health that would prevent 67 million unintended pregnancies and reduce induced abortions from 48 million to 13 million, maternal deaths by 76,000 per year, newborn deaths from 2.9 million to 660,000 per year and HIV infections in newborns from 130,000 to 9,000 . estimated 214 million women in the developing world want to delay or prevent pregnancy but are not using a modern method of contraception [1-3]

Through the use of Family planning, young women can delay or space the pregnancy. After a live birth, family planning helps a woman space her next pregnancy for at least two years or approximately three years between births. With such spacing, children are more than twice as likely to survive infancy and are healthier and allow the mother to provide the benefits of breast feeding longer and spend more time with each child which contributes to the child's physical health and mental and emotional development. It has saved the lives of millions of mothers and their children through the prevention of high-risk pregnancy or unplanned pregnancy [1, 4-6].

For these women who want to prevent unplanned pregnancy, long acting and permanent contraceptive methods (LAPM) are 
very safe, effective and affordable methods which do not require daily use or repeated visits to get the supply. These LAPM include contraceptive methods like Implants and intrauterine contraceptive device (IUCDs) and tubal ligation which are the most effective contraceptive $(99 \%$ or more unplanned pregnancy protection rate). Their effectiveness vary based on their type (effective for 12 years (IUCDs), for three to five years based on the type (Implants) and for permanent prevention of pregnancy (tubal ligation) [4, 6-9].

Provision of LAP methods are central to meet growing levels of demand for family planning and address sexual and reproductive health needs of women's as it saved the lives of millions of mothers and their children through the prevention of high-risk pregnancy or pregnancy which is not planed [5, $7,9,10]$.

Worldwide, around 10 million adolescent girls marry each year. These young brides are not fully matured physically and their body is not prepared for pregnancy however they are pressured to begin to have children. Study show that the age at which a woman has her first pregnancy affects the health and life of a mother and her baby. The percentage of teenagers who have given birth or are pregnant with their first chilled be $13 \%$ in Ethiopia, $14 \%$ at study area and 3\% at Addis Ababa which can leads to obstetric complication during, intra-partum and after pregnancy to both mother and new born $[8,11,12]$.

High fertility directly or indirectly affects environment, socio-economic and the health of country which can be prevented by contraceptive use. The global fertility rate is 2.5 United States of America, 1.9 Sub-Saharan Africa, 4.7 Asia and Latin America and the Caribbean (2.2), Europe 1.6, while the total fertility rate (TFR) in Ethiopia is 4.6 children per woman $[12,13]$.

The average contraceptive prevalence rate of sub-Saharan Africa was 22\% and South Asia (53\%) [2]. Kenya has CPR $50 \%$, Ethiopia has 36\% CPR ( $8 \%$ implant, $2 \%$ IUCD and $<1 \%$ tubal ligation). the percentage of currently married women aged between 15-49 who wants no more children (including women who are sterilized) were $37 \%[13,14]$.

The total demand for family planning increase with time periods but Substantial gaps still persist the utilization and demand for modern methods among couples who want to prevent pregnancy and demand for contraception. In 2015, less than half of total demand for family planning was being met with modern methods in 54 countries (34 of which are in Africa). In an additional 76 countries, less than $75 \%$ of total demand was met by use of modern methods. In Ethiopian 58\% women age 15-49 have a demand for family planning; $35 \%$ want to space births, and $23 \%$ want to limit births $[8,13,15]$.

The contraceptive prevalence rate varies throughout the world. The finding shows that, CPR was much lower in the least developed countries (40\%) and Africa has CPR 33\% [8] Study conducted in Iran revealed that $21.4 \%$ CPR among married women (14.1\% IUCD and 6\% tubal ligation) [16]. study conducted in Bungoma East Sub-County of Kenya indicates $7.9 \%, 1.2 \%$ and $0.8 \%$ for implants, sterilization, and IUCD respectively. The finding of Study conducted in
Pakistan shows CPR $35 \%$ of which $17 \%$ used IUCD) [17, 19].

\subsection{Knowledge of LAPM}

The result of the study conducted in Uganda shows that $25.8 \%$ of the respondent knows LAPM [21]. Study conducted in The Jabalpur city located in Madhya Pradesh state of India $93.6 \%$ knew about female sterilization and $48.3 \%$ IUCD[22].

The report from 2010 Malawi Demographic and Health Survey indicates that $72 \%$ of participants have knowledge about IUCD[23] and the finding conducted on LARC in Luanda Angola, shows 39.6\% of married women knew about IUDs and 38.6\% knew about implants respectively [23, 24].

Study conducted in Bale Goba (Ethiopia) show that $47.7 \%$, $15.8 \%, 3.85 \%$ knew implant, IUCD and tubal ligation respectively. The finding of the study conducted in western Ethiopia indicates $82.5 \%$ knew LAPM. The result of study done in Debre-markose shows that $74.4 \%$, and $44.4 \%$ knew the advantage of implant and IUCD respectively and more than half didn't knew the advantage of tubal ligation $[5,20$, 25].

\subsection{Source of Information}

Report of Malawi DHS indicates that, $84.9 \%$ married women heard about implant, $39.9 \%$ about female sterilization and $38.4 \%$ IUCD. This report indicates that, $93 \%$ of women obtained information from health institution [24].

The result of the Study conducted in The Jabalpur city located in Madhya Pradesh state of India indicates Television/Radio) has influential effect on the contraceptive use [22]. Study in Pakistan highlight as health workers as source of information about contraceptive [26].

The finding of the Study done at Bale-Goba revealed that, HEW $(89.9 \%)$, friends $(28.1 \%)$, health workers provider $(24.2 \%)$ and radio $(22.1 \%)$ were the main source of information related to LAPM. study done at debre-markose indicates that Health care provider $(63.8 \%)$ and television $(61.5 \%)$ were the most commonly mentioned source of information related to LAPM. The finding of the study done in west Ethiopia shows that $82.5 \%$ of the study participant was ever heard about LAPM and main source of information are health care provider, Radio/TV and friends $(78.2 \% .72 .5 \%$ and $24.2 \%$ respectively) $[5,20,25]$

\subsection{Factors Affecting Long Acting and Permanent Contraceptive Methods}

The promotion of information, counseling and services for a range of methods are necessary to ensure that different pregnancy prevention methods (for limiting, delaying pregnancy, preventing pregnancy) in the post-partum period and so are met with the most appropriate and effective methods [8].

Study conducted in Uganda and resource limited setting indicates that fear of side effects, lack of knowledge of related to Contraceptive methods were barriers for LAPM 
utilization. The finding also indicates that, Husband opposition, Myths /misconception related to the contraception, age of married women, and desired numbers of children were factors for non-use of contraception. This study finding pointed out that, the utilization of LAPM were affected by educational level (14\% in those with primary or no education, $16 \%$ in those with secondary education, and $40 \%$ in those with tertiary education) [9, 21]. From the study finding in Mwanza, Tanzania shows as fear of side-effects and lack of information related to LAPM were barriers for LAPM for utilization of LAPM [27].

The result study conducted in Malawi indicates that number of living children, religion, household wealth status, partners' education and heard about family planning are factors for contraceptive methods [24]. The result of Study conducted in Congo on LARC shows provider bias, low clinical competency, lack of knowledge among users, and the influence of partners and other family members in family planning decision making are barriers for contraceptive use [28].

Study conducted in Bale-eco-region shows that religious opposition $(55.9 \%)$, husband opposition (17.5 and fear of side effect $(25.5 \%)$ are main reason women didn't intend to use RLAC. The result of study conducted at Debremarkose show that, inter pregnancy spacing $(55.9 \%)$ and limiting $(28.2 \%)$ were the main reason the respondent were intending to use LAPM. The result of this finding shows that, $45.3 \%$ of the couple discussed about LAPM together and $54.1 \% \%$ of their husband allow them to use LAPM. From the result of this finding, Fear of side effect $(58.4 \%)$, preferring short term $(36.3 \%)$ and religious prohibition $(24.2 \%)$ are reason for not to use LAPM. The finding done in the West Ethiopia shows that, $81.5 \%$ of the participant ever discussed about LAPM and decided jointly and Side effect (38.9\%). The finding shows that, rumors about LAPM $(49 \%)$ were main reason for not using LAPM in the future.[20, 25, 29].

EDHS 2016 report indicates the CPR of the region as $(28 \%$ benishangule-gumuze, 50\% Addis Ababa, 47\% Amara, 40\% SNN, 35\% Tigray, 35\% Gambella and 29\% Harari [13].

\subsection{Problem Statement}

Despite the complication/ death related to pregnancy, the utilization of contraceptive method especially LAPM were remain the least utilized method among reproductive age women. Study shows that 120 million women worldwide want to prevent unwanted pregnancy but they and their partner do not the contraception of their choice. Utilization of LAPM prevent 67 million unintended pregnancies and reduce induced abortions from 48 to 13 million, maternal deaths by 76,000 per year, newborn deaths from 2.9 to 0.66 million per year $[3,8]$.

While current challenges to health throughout the world are many and serious, the need to control one's own fertility probably touches more lives than any other health issue. Report show global fertility rate of 2.5, USA 1.9, Asia 2.8 and Africa 5.6, Ethiopia 4.6 and Benishangule-Gumuze 4.4\% $[1,8,13]$.
Short-term and reversible methods are more common in Africa and Europe whereas long-acting or permanent methods are more common in Asia and Northern America. Less than 10 per cent of married or in-union women of reproductive age were using contraception in Chad, Guinea and South Sudan and five countries in Eastern Africa (Kenya, Malawi, Rwanda, Zambia and Zimbabwe) had CPR of 50\% or more in 2015 [4, 15].

Ethiopia Demographic Health Survey 2016 (EDHS 2016) indicates CPR of $36 \%$ (8\% implant, $2 \%$ IUD and $<1 \%$ tubal ligation). The total demand for family planning in Ethiopia were $58 \%$ (35\% want to space births, and $23 \%$ want to limit births). It is known that despite the increased demands of women for LAPM to long term spacing or even limiting the child bearing, the utilization of short term remain high in the country despite their lower effectiveness rate of unplanned pregnancy protection. In the study area, the fertility rate and teenage pregnancy were higher compared to the other region of Ethiopia. This has its own effect on rapid population growth, malnourishment and negative impact on the environment and reproductive organ related morbidity and mortality. However the reason for higher demand especially at the study area and lower utilization of contraception were remain unknown. There for this study aims to assess demand for long acting and permanent contraceptives methods and associated factors among married women visting Assosa governmental health institution for family planning. Mixed study.

\section{Methods}

\subsection{Study Setting and Sample}

The study was conducted in Assosa town governmental health institution which is located $561 \mathrm{~km}$ west from Addis Ababa. The town is bounded in the south by mao-komo special wereda, on the West by Sudan, on the north-east by kamashi. The town has one university, one poly Technique College, one health center and hospital. Based on the 2013 major town population estimation, Assosa town has 35,752 total populations $(17,669$ male and 18,084 female).

Assosa Hospital provides service for client referred from Assosa zone and Oromya region like Mendi and Begi. It provides family planning service, ANC, delivery service, postnatal service and comprehensive abortion service and other medical and surgical care service. Cross sectional institutional based study was used to conduct the study in Assosa hospital and Assosa health center from April 12-May 10/2019 to asses demand for long acting and permanent methods and associated factors among reproductive age women visiting the two institution. Source population was all married women found in Assosa town aged 15-49 years and study population was Married woman's aged 15-49 who visits Assosa governmental health institution for family planning service

\subsection{Sampling Procedure and Sample Size}

The sample size was calculated by using single population 
proportion formula by considering 0.181 proportion for demand for LAPMs[5], 95\% confidence level, 5\% Margin of error and $10 \%$ non-response rate i.e.

$$
\begin{gathered}
\mathrm{n}=\left(\mathrm{z} \frac{\alpha}{2}\right)^{2} \frac{\mathrm{p}(1-\mathrm{p})}{\mathrm{d}^{2}} \\
=1.96^{2} \frac{0.181(1-0.181)}{0.05^{2}}=228
\end{gathered}
$$

Where

$\mathrm{n}=$ sample size

$\mathrm{Z}=\mathrm{is}$ the level of significance corresponding to $95 \%$ confidence interval (1.96)

$\mathrm{P}=$ proportion for demand for $\mathrm{LAPMs}=0.181$

$\mathrm{D}=$ the absolute precision required $=5 \%$

So the total sample size was 251 with $10 \%$ non-response rates. The samples were allocated to the health center and hospital proportionally based on their monthly plan of family planning under the coverage. All married women who visit the two health institution were selected randomly to get 251 total sample size (102 Hospital and 149 Health center). Sample size for qualitative method was based on the saturation of information.

\subsection{Operational Definition}

Demand for LAPM: according to this study, it is defined as an expressed need of married women to utilize LAPM.

Reversible Long acting contraceptive: contraceptive methods which used temporarily

Permanent methods of contraceptive: contraceptives methods used to limit pregnancy

To delay pregnancy: contraceptive used to prevent the first pregnancy (implant and IUCD).

To space pregnancy: contraceptive methods used to make gap between the first pregnancy and the next pregnancy (implant and IUCD).

To limit pregnancy: contraceptive methods used to control pregnancy permanently(tubal ligation).

\subsection{Variable}

\subsubsection{Dependent Variable}

\author{
Demand for LAPM
}

\subsubsection{Independent Variable}

Socio demographic and economic characters (age, religion, occupational status).

Behavioral characteristics (method awareness, partner involvement, myths and misconception, intention to use LAPM).

Source of information about LAPM (health professionals, Media. health extension workers) printout materials

Method factors (ease of use, side effects, fear of the method used).

\subsection{Inclusion Criteria}

All married women's of reproductive age group who visit family planning unit and volunteer to participate.

\subsection{Data Collection Procedures}

Data was collected by face to face in-depth interview by using structured questionnaire adapted from the literature review. The questionnaire was prepared in English and translated in to Amharic and back to English. Four trained health care provider (two BSC midwife and two diploma midwives) were used for data collectors. Two BSC midwives, one from each health institution was used as supervisor during data collection period. Pre -test of the questionnaire was done on $5 \%$ of the sample on married women at Bambasi health center (nearby Assosa town health center) to identify any ambiguity, consistency and acceptability of questionnaire, and then necessary corrections was made before the actual data collection.

For the qualitative method, a total of seven in-depth interviews were conducted with purposively selected key informant to explore the barriers for non-use of LAPM. These key informants were selected based on the socio demographic variation. The interview was conducted by principal investigator (PI) and supervisor. Both audio record and note was taken.

\subsection{Data Quality Control}

Quality of the data was controlled through continuous checking questionnaires for the completeness. The questionnaire was transferred to Amharic language to maintain consistency and pre-test was given before actual data collection to check any difficulty and then after the possible correction, data collection was started. Data collectors and supervisors were trained intensively for one day on the title of the study, objective, data collection tool, procedure, informed consent and methods of sample selection.

The in-depth interview were conducted on the selected key informant in the private room selected for the interview purpose. The interview was started after the participants were informed about the aim of the study and the privacy was assured. The principal investigator and one supervisor conducted the interview. The recorded data were translated to the note after repeated listening and coding of the data to ensure a degree of standardization. Final transcripts were compared against note takers' notes to ensure quality. Finally, the report was done to support the quantitative data based on the participant report after coding and checking the similarity and difference between the note taken from codded data and note takers note.

\subsection{Data Analysis}

The collected data was cleaned, coded, and entered in to EPI info 7 and then exported to SPSS version 24 for further analysis. Bivariate analysis was done to determine factors influencing demand for LAPM and variables which was found to have significant association at $\mathrm{p}$-values $<0.2$ in bivariate analysis was taken to multivariate regression to test effect of independent variables on dependent variable. Proportion, percentage, frequency distribution, logistic regression, odds ratio with $95 \%$ confidence interval at $\mathrm{P}<0.05 \%$ was used in describing the data. The results were displayed using text, tables and figures.

Qualitative data was transcribed verbatim, coded and analyzed using thematic analysis to support quantitative 
analysis and presented in the narrative. Finally the findings were triangulate with the quantitative result during write up.

\subsection{Ethical Consideration}

Formal letter of cooperation was written from Addis Ababa University to Assosa town health institution administrator and informed consent was obtained from each study participant after the objectives of the study were fully explained by their local languages. The participant was informed the aims of data collection and informed as the sensitive issue was kept secret and after getting consent and insuring confidentiality, the data collectors start to collect the data. Also they informed as they have the right not to participate and failure to participation do not affect any care and service they get now and in the future and the collected data was stored in a file, without the name of study participant (anonymously), but code will be assigned for each and was not disclosed to others except to the principal investigator.

\subsection{Dissemination of the Study Result}

The result of the study will be presented to School of Nursing and Midwifery. Dissemination of result will be made through Addis Ababa University College of health science, $\mathrm{CHs}$ library, Assosa health bureau, $\mathrm{MOH}$ and Assosa health institution administration. Also effort will be done to publish in peer review journal

\section{Result}

\subsection{Socio Demographic Characteristics of Study Participant}

From the total of 251 participant, $96(38.2 \%)$ were at age group of 25-29 years. The result shows that, 104 (41.4\%) of the respondent completed secondary education. Table 1

Table 1. Socio demographic characteristics of married women who visited Assosa governmental health institution.

\begin{tabular}{|c|c|c|c|}
\hline Variable & & Frequency & $\%$ \\
\hline \multirow{6}{*}{ Age } & $15-19$ & 23 & 9.20 \\
\hline & $20-24$ & 83 & 33.1 \\
\hline & $25-29$ & 96 & 38.2 \\
\hline & $30-34$ & 25 & 10 \\
\hline & $35-39$ & 21 & 8.4 \\
\hline & $40-44$ & 3 & 1.2 \\
\hline \multirow{6}{*}{ Ethnicity } & Berta & 45 & 17.9 \\
\hline & Shinasha & 32 & 12.7 \\
\hline & Oromo & 71 & 28.3 \\
\hline & Tigre & 22 & 8.8 \\
\hline & Amara & 67 & 26.7 \\
\hline & Others & 14 & 5.6 \\
\hline \multirow{3}{*}{ Religion } & Orthodox & 116 & 46.2 \\
\hline & Muslim & 93 & 37.1 \\
\hline & Protestant & 42 & 16.7 \\
\hline \multirow{4}{*}{ Participant educational status } & Cannot read and write & 20 & 8 \\
\hline & Primary education & 41 & 16.3 \\
\hline & Secondary education & 104 & 41.4 \\
\hline & Above secondary education & 86 & 34.3 \\
\hline \multirow{6}{*}{ occupational status of study participant } & house wife & 102 & 40.6 \\
\hline & Governmental employee & 66 & 26.3 \\
\hline & Merchant & 21 & 8.4 \\
\hline & Farmer & 17 & 6.8 \\
\hline & daily laborer & 11 & 4.4 \\
\hline & Others & 34 & 13.5 \\
\hline \multirow{4}{*}{ Husband educational status } & cannot read and write & 15 & 6.0 \\
\hline & Primary school & 55 & 21.9 \\
\hline & Secondary school & 35 & 13.9 \\
\hline & Above secondary school & 146 & 58.2 \\
\hline \multirow{5}{*}{ Husband occupational status } & Governmental employee & 117 & 46.6 \\
\hline & Merchant & 53 & 21.1 \\
\hline & Farmer & 24 & 9.6 \\
\hline & daily labourer & 39 & 15.5 \\
\hline & Others & 18 & 7.2 \\
\hline \multirow{4}{*}{ Participant average monthly income } & $<100$ & 12 & 4.8 \\
\hline & $<100-499$ & 20 & 8 \\
\hline & $500-1400$ & 52 & 20.7 \\
\hline & $>1400$ & 167 & 66.5 \\
\hline
\end{tabular}

\subsection{Awareness, Source of Information and Knowledge About LAPM}

The finding of this study shows that, majority 197 (78.5\%) of the participant had information related to LAPM and health care provider was the main source of information 78 (31.1\%). The result shows that, $182(72.5 \%)$ knows any of the LAPM and 
tubal ligation was least known at the study area 69 (27.5\%). Table 2

Table 2. Awareness of LAPM among married women who visited Assosa governmental health institution.

\begin{tabular}{|c|c|c|c|}
\hline Variable & & Frequency & $\%$ \\
\hline \multirow{2}{*}{ Ever heard LAPM } & Yes & 197 & 78.5 \\
\hline & No & 54 & 21.5 \\
\hline \multirow{3}{*}{ Source of information } & From HEW & 63 & 25.1 \\
\hline & From friends & 30 & 12.0 \\
\hline & From TV/radio & 26 & 10.4 \\
\hline \multirow{2}{*}{ Know any LAPM } & Yes & 182 & 72.5 \\
\hline & No & 69 & 27.5 \\
\hline \multirow{2}{*}{ Know implant } & Yes & 182 & 72.5 \\
\hline & No & 0 & \\
\hline \multirow[b]{2}{*}{ Know Use of implant } & To limiting pregnancy & 21 & 8.4 \\
\hline & To delaying pregnancy & 7 & 2.8 \\
\hline \multirow{2}{*}{ Know IUCD } & Yes & 126 & 50.2 \\
\hline & No & 58 & 23.1 \\
\hline \multirow{3}{*}{ Know Use of IUCD } & To limit pregnancy & 14 & 5.6 \\
\hline & To delaying pregnancy & 6 & 2.4 \\
\hline & To spacing pregnancy & 106 & 42.6 \\
\hline \multirow{2}{*}{ Know BTL } & Yes & 69 & 27.5 \\
\hline & No & 117 & 46.6 \\
\hline \multirow{2}{*}{ Know Use of BTL } & To limit pregnancy & 49 & 19.5 \\
\hline & Spacing pregnancy & 20 & 8 \\
\hline
\end{tabular}

Note:-BTL- bilateral tubal ligation $I U C D$ - intrauterine device.

\subsection{Reproductive History of Study Participant}

The finding shows that, $172(68.5 \%)$ of the study participant had desire for more child in their future and $147(58.6 \%)$ of the participant want to have children after 2-5 years. Table 3

Table 3. Reproductive history of married women who visited Assosa governmental health institution.

\begin{tabular}{|c|c|c|c|}
\hline Variable & & Frequency & $\%$ \\
\hline \multirow{2}{*}{ Ever given birth } & Yes & 200 & 79.7 \\
\hline & No & 51 & 20.3 \\
\hline \multirow{4}{*}{ Numbers of child } & One & 24 & 9.6 \\
\hline & Two & 40 & 15.9 \\
\hline & Three & 79 & 31.5 \\
\hline & $>=$ five & 11 & 4.4 \\
\hline \multirow{2}{*}{ Desire for additional numbers of children } & Yes & 172 & 68.5 \\
\hline & No & 28 & 11.2 \\
\hline \multirow{3}{*}{ Time period to have child } & After one year & 29 & 11.6 \\
\hline & After 2-3 years & 75 & 29.9 \\
\hline & After $4-5$ years & 72 & 28.7 \\
\hline
\end{tabular}

The result of this finding shows that, more than half 147 (58.6\%) of the study participant ever used at least one of the LAPM and $116(46.2 \%)$ of participant utilized contraceptive implant. Figure 1 


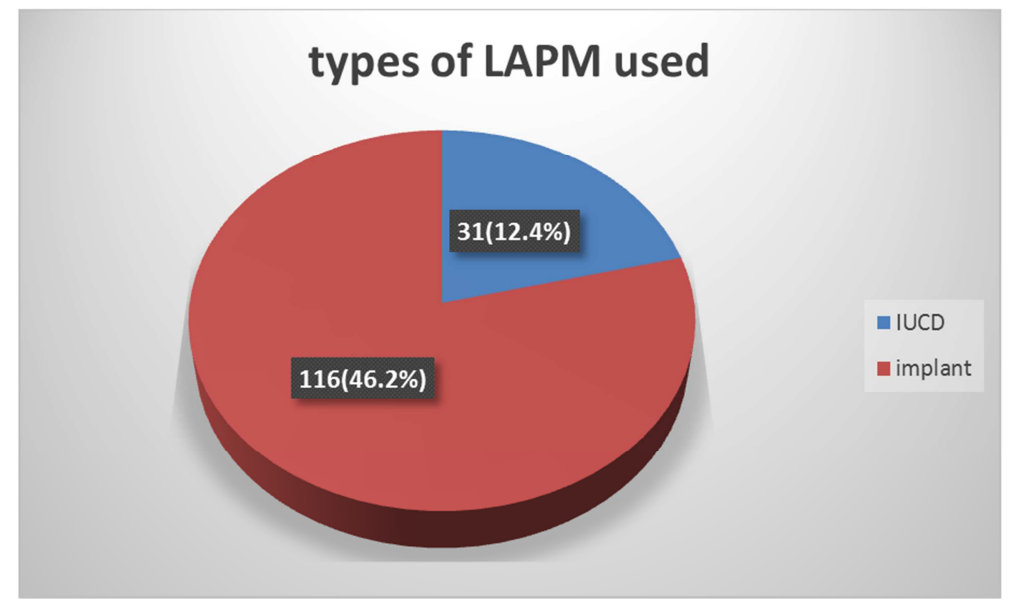

Figure 1. Utilization of LAPM by married women who visited Assossa governmental health institution

\subsection{Demand for LAPM, Reason for USe, Reason for Nonuse and Couple Discussion About Any LAPM}

From this study result, $157(62.5 \%)$ of married women had demand for LAPM. $135(53.7 \%)$ of the participants want to space inter-pregnancy. Fear of side effect 34 (13.5\%) and preferred short term methods were main reason for nonutilization of LAPM. Majority of the respondent 188 (74.9\%) were ever discussed about any of LAPM with their husband. Table 4

The result of in-depth interview also revealed that, client had an expressed need to utilize LAPM but they failed to utilize it as contraceptive methods of their choice due to some reasons like fear of side effect, prefer short term method, religious prohibition and fear of husband. "I do not want to use LAPM due to its side effect. Currently I am using contraceptive implant, it cause menses irregular, I faced headache after I started it, it weaken my hand and influence my daily work so why I come to remove it today." /I4, client / "They reported that, using implant cause menses irregularity, cause headache/dizziness, brings about weight gain/loss and brings about behavioral change."/I2. health care provider / "Most of the time client takes contraception without the permission of their husband, due to this they want to use the invisible type of contraceptive methods like Depo-Provera." /I1. Health care provider /

Table 4. Demand for LAPM, reason for use and non-use and participant discussion about LAPM, among married women visiting Assosa governmental health institution.

\begin{tabular}{|c|c|c|c|}
\hline Variable & & Frequency & $(\%)$ \\
\hline \multirow{2}{*}{ Intention to use LAPM } & YES & 157 & 62.5 \\
\hline & No & 94 & 37.5 \\
\hline \multirow{2}{*}{ Reason to use LAPM } & To delay pregnancy & 22 & 8.8 \\
\hline & To space pregnancy & 135 & 53.7 \\
\hline \multirow{5}{*}{ Reason for non-use of LAPM } & Prefer short term method & 22 & 8.76 \\
\hline & Fear of side effect & 34 & 13.5 \\
\hline & Fear of husband & 11 & 4.4 \\
\hline & Went to become pregnant & 2 & 0.8 \\
\hline & Lack of adequate knowledge & 14 & 5.57 \\
\hline \multirow{2}{*}{ Ever discussed about LAPM with husband } & Yes & 188 & 74.9 \\
\hline & No & 63 & 25.1 \\
\hline \multirow{2}{*}{ Husband attitude toward LAPM use } & Allow to use & 147 & 58.6 \\
\hline & Do not allow to use & 43 & 17.1 \\
\hline \multirow{2}{*}{ Decision maker from both couple to use LAPM } & Wife only & 81 & 32.3 \\
\hline & Both couple & 161 & 64.1 \\
\hline
\end{tabular}

\subsection{Myth/Misconception Reported by Study Participant}

The result of this study shows that, $65(25.9 \%)$ of the respondent belief as using implant cause weakness of hand/arm and $42(16.7 \%)$ belief as using implant brings about behavioral change. These the finding revealed that, 27 $(10.8 \%)$ of the respondent belief that, using IUCD interfere with sexual activity and $14(5.6 \%)$ belief that IUCD cause reproductive organ infection. also this study shows that, 53
(21.1\%) of the participant belief as tubal ligation need major operation and $49(19.5 \%)$ belief as tubal ligation procedure cause severe pain. Table 5

The study finding was supported by the result of in-depth interview. The key informant pointed out that, client has an expressed demand to utilize LAPM but did not want to utilize due to some perceived misconception/rumors related to LAPM they heard from the community.. "IUCD is not preferred by client due to different misconception related to 
the contraceptive methods. They belief as IUCD cause infertility, the procedure need major operation, cause severe pain during and after insertion, do not give comfort during sexual activity, cause reproductive organ infection and may disappear after insertion." /I1, health care provider / "Some client said that implant needs major operation and the operation site takes long healing duration. It also move to the other body part like to brain and heart. Implant cause numbness/weakness of hand which can interfere with daily work."/M2. Health care provider/ "There where client who want to limit the pregnancy permanently but utilize short term methods due misconception/rumors heard from the community. They belief that tubal ligation need major operation, its wound healing take long time, it decrease sexual desire and its procedure cause severe pain."/ $[3$, health care provider/

Table 5. Myth/misconception related to LAPM among married women who visit Assosa governmental health institution.

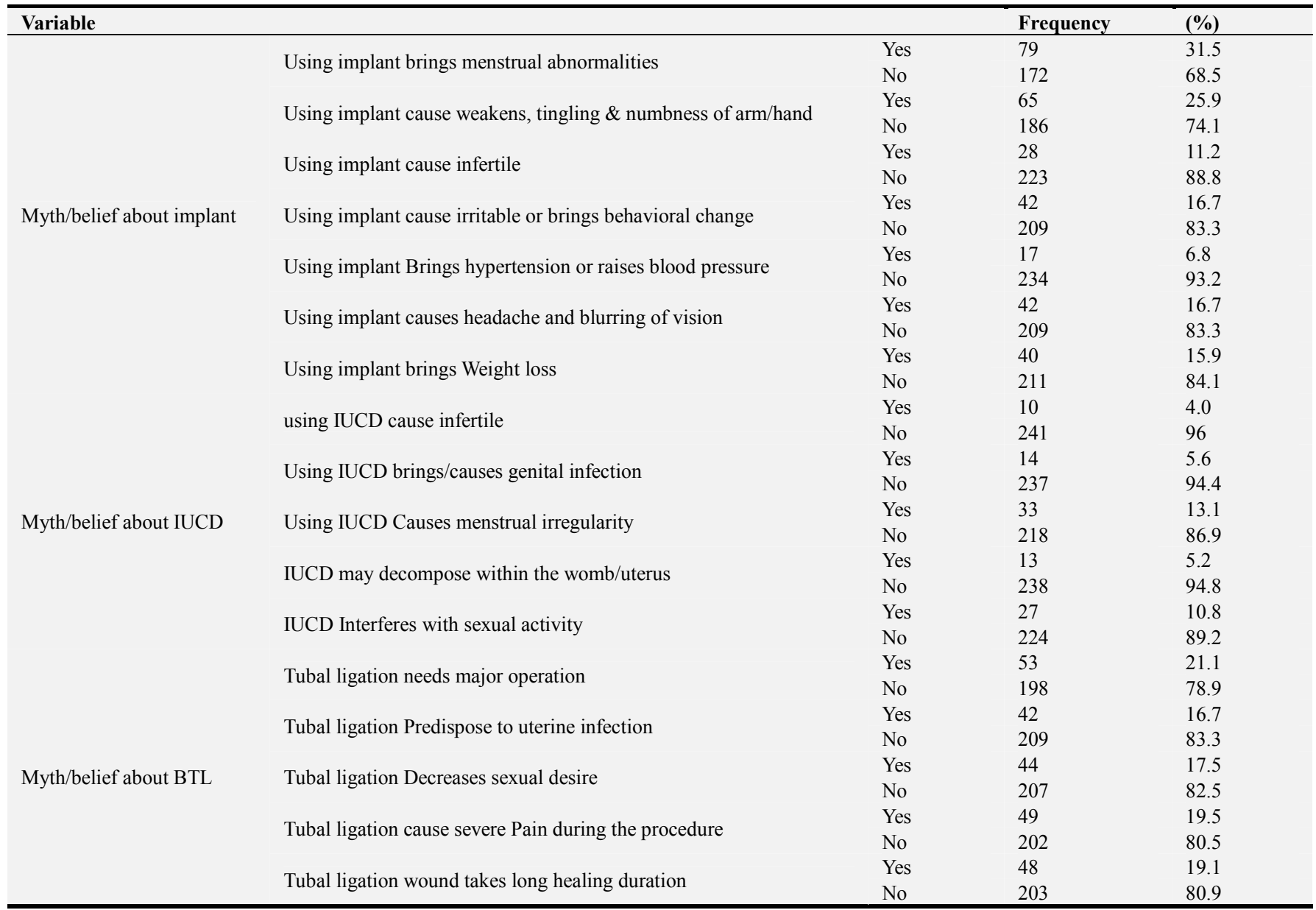

Table 6. factor associated with demand for LAPM among married women visiting Assosa governmental health institution.

\begin{tabular}{|c|c|c|c|c|c|c|c|}
\hline \multirow{2}{*}{ Variable } & & \multicolumn{2}{|c|}{ Demand for LAPM } & \multicolumn{2}{|l|}{ Bivariate } & \multicolumn{2}{|l|}{ Mulitivarate } \\
\hline & & yes & No & Crude OR 95\%CI & P-value & Adjusted OR 95\%CI & p-value \\
\hline \multirow{3}{*}{ Participant education } & Cannot read and write & 12 & 8 & $2.20(.789-6.131)$ & .132 & $0.482(0.143-1.627)$ & 0.24 \\
\hline & Primary education & 26 & 15 & $1.904(.848-4.274)$ & .119 & $0.622(0.249-1.558)$ & 0.311 \\
\hline & Secondary school & 54 & 50 & $3.175(1.69-5.968)$ & .00 & $.289(0.137-.608)^{*}$ & 0.001 \\
\hline \multirow{2}{*}{ Heard LAPM } & Yes & 135 & 62 & $.349(.188-.646)$ & 0.001 & $2.503(1.188-5.23)^{*}$ & 0.016 \\
\hline & No & 23 & 31 & 1 & & . & \\
\hline \multirow{2}{*}{ Know any LAPM } & Yes & 132 & 50 & $.215(.119-.388)$ & 0.000 & $2.62(1.295-5.299)^{*}$ & 0.007 \\
\hline & No & 26 & 43 & & & & \\
\hline \multirow{2}{*}{ Ever used LAPM } & Yes & 112 & 35 & $.257(.15-441)$ & 0.00 & $3.37(1.805-5.29)^{* *}$ & 0.00 \\
\hline & No & 46 & 58 & 1 & & . & . \\
\hline \multirow{2}{*}{$\begin{array}{l}\text { Couple discussion } \\
\text { about any LAPM }\end{array}$} & Yes & 132 & 56 & $.306(.169-552)$ & 0.00 & $2.07(1.027-4.163)^{*}$ & 0.042 \\
\hline & No & 26 & 37 & 1 & & 1 & \\
\hline \multirow{4}{*}{ Husband occupation } & Governmental employee & 80 & 37 & $0.37(0.135-1.014)$ & 0.153 & $7.269(1.096-11.6)$ & 0.054 \\
\hline & Merchant & 29 & 24 & $0.662(0.226-1.94)$ & 0.452 & $1.911(0.543-6.725)$ & 0.313 \\
\hline & Farmer & 16 & 8 & $0.40(0.114-1.408)$ & 0.154 & $4.588(1.042-20.19)$ & 0.44 \\
\hline & Daily laborer & 24 & 15 & $0.50(0.50-1.51)$ & 0.23 & $3.468(0.97-13.267$ & 0.069 \\
\hline
\end{tabular}

Note $*$ =significant at $\mathrm{p}<0.05 * *=$ significant at $\mathrm{p}=0.00$, reference $=$ no. 


\subsection{Associated Factor's Bivariate and Multivariate Result}

The result of this finding show that, Respondent who had secondary school education were $71.1 \%$ lower odds of demand for $\mathrm{LAPM} \quad(\mathrm{AOR}=.289,95 \% \mathrm{CI}=(0.137-.608))$. Women's who had information about any of the LAPM from different source of information were significantly associated with demand for LAPM (AOR $=2.503,95 \% \mathrm{CI}=1.188$ 5.2274). Women's who knows any LAPM were significantly associated with demand for LAPM (AOR $=2.62,95 \%$ $\mathrm{CI}=1.295-5.299$ ). From this study finding, women's who had ever used any LAPM were significantly associated with demand for $\mathrm{LAPM} \quad(\mathrm{AOR}=3.369,95 \% \mathrm{CI}=1.805-5.291)$. Respondents who ever discussed about any LAPM with their husband were significantly associated with LAPM $(\mathrm{AOR}=2.067,95 \% \mathrm{CI}=1.027-4.163)$. Table 6

\section{Discussion}

The finding of this study shows that, Demand for long acting and permanent method was $62.5 \%$. The result was higher when compared to the result reported by EDHS 2016 $(58 \%)$, study done in north-west Ethiopia (17\%), Debremarkose (52.4\%) and Bale Goba (18.1\%). These discrepancies might be due to increased client access to information regarding to the contraception especially LAPM and their use through time or might be due to different study periods $[5,13,20,25]$.

The finding of this study show that, the main reason that client want to utilize LAPM were to space inter-pregnancy $(54.2 \%)$. The finding Was higher than the result of study done in north-western Ethiopia (16.4\%) [20] and report of EDHS 2016 (35\%). These the possible justification for the discrepancy between the findings might be due to increased service delivery setting with respect to trained service providers. Also, the variation may be due to the different study period.

Fear of side effect (13.5\%), preferred short term method $(8.8 \%)$, religious prohibition $(4.4 \%)$, want to become pregnant $(0.8 \%)$ and lack of adequate knowledge about LAPM (5.6\%) were some of the reason for non-utilization of LAPM as contraceptive methods of their choice. On the other hand perceived misconception related to LAPM developed from the community or from past self-experience were other challenging factors to utilize LAPM despite the expressed demand for those contraceptive methods. The result of this study shows that the prevalence of misconception related to utilizing contraceptive implant (cause infertility (11.2\%), cause numbness of hand/arm $(25.9 \%)$, cause behavioral change (16.7\%)) and IUCD related misconception as (cause infertility $(4 \%)$, decompose in the uterus $(5.2 \%)$, interfere with sexual activity $(10.2 \%)$ and misconception related with BTL as (cause severe pain during the procedure (19.5\%), need major operation $(21.1 \%)$ and decrease desire for sexual activity $(17.5 \%))$. These, the fore mentioned above misconception/rumors related to the utilize LAPM were supported by the result of qualitative in-depth interview.

But there where discrepancies between this study result and the result of the study done in Bale-Goba (religious opposition (55.9\%), husband opposition (17.5 and fear of side effect (25.5\%) [5], Debremarkose(Fear of side effect (58.4\%), preferring short term (36.3\%) and religious prohibition $(24.2 \%)$ [20] and western Ethiopia (Side effect (38.9\%), rumors related with LAPM (49\%)) [25]. These, LAPM related misconception/ rumors were also mentioned by the study result conducted in Iran [16]. The possible reason for such discrepancies between the studies may be due to the fact that, there might be increased provision of information related to misconceptions about LAPM in the study area. Also the variation may be due to different study period.

The finding of this study shows that, majority of the study participant had ever given birth (79.7\%) and more than half of those who gave birth $(41.5 \%)$ didn't want to have child within three years. This may indicates as there is need for assessing client contraceptive need inline with their reproductive plan. Also this may indicates as there be need for disseminating the adequate information related with the types LAPM and their duration of services.

The result of this study shows that, the majority $(78.5 \%)$ of the participant had ever heard about any of the LAPM which is significantly associated with demand for LAPM (AOR $=2.505,95 \% \mathrm{CI}=1.192-5.265)$. The result of this study were higher than the result reported by Malawi DHS (74.6\%) [24] And Amuru district, Northern Uganda (76.3\%) [21]. The possible reason for the variation might be due to different study area and periods. But result of this finding was lower than the result of the study done in west Ethiopia (82.5\%) [25]. The discrepancies might be the fact that client in the study area has limited accessibility to the information related to contraception especially LAPM or might be there were limited source of information at the study area.

Different study shows that, Client can get information from different source that help them to choose the contraceptive methods of their choice easily [26, 28]. The finding of this study result indicates that, health care provider $(31.1 \%)$ and health extension workers $(25.1 \%)$ were the main source of information related to LAPM. There where discrepancy between the result of this study finding and the result of study finding conducted in the West Ethiopian which shows that (health care provider $(78.2 \%)$, Radio/TV (72.5\%) [25] and study result of Debre-markose (Health care provider $(63.8 \%)$ and television/radio $(61.5 \%)$ ) [20]. These the possible reason for such variation might be, there were limited client access to the source of information in the study area. Also it might be an indication that, there were limited source of information related to LAPM in the study area.

The increased knowledge about contraceptive method help client to easily choose the contraceptive methods of their choice according to their reproductive plan to prevent unplanned pregnancy. The result of this study shows that, majority $(72.5 \%)$ of the study participant knew any of long acting and permanent methods which also positively 
associated with demand for LAPM $\quad(\mathrm{AOR}=2.809$, $95 \% \mathrm{CI}=1.41-5.595)$. This result was higher than study conducted in Uganda (25.8\%) [21]. The possible reason for the variation of the result might be due to different geographical location, increased globalization and may also due to different study period. But the result of this finding was lower than the result of the study conducted in the western Ethiopia (82.5\%) [25]. This discrepancies might indication that, there were limited access of client to the education related to LAPM given by different concerned body like health extension worker in the community, at the health post or it might be indication that, there were limited provision education related to LAPM by any concerned body in the study area.

Knowing the types contraceptive help client who want to use family panning to easily choose the contraceptive methods which correspond with their reproductive plan. This finding revealed that, $72.5 \%, 61.4 \%$ and $27.55 \%$ knows contraceptive implant, IUCD and tubal ligation respectively. This result was higher than the result of study done in Angola (39.6\% IUD and $38.6 \%$ implants) [30], India (48.3\%IUCD) [22] and Bale-Goba (47.7\% implant, $15.8 \%$ IUCD and 3.85\% tubal ligation) [5]. The discrepancy might be due to different study period.

In this study finding, the utilization rate of LAPM were $58.6 \%$ which is positively associated with demand for LAPM use $(\mathrm{AOR}=3.201,95 \% \mathrm{CI}=1.731-5.917)$. The result of this finding was higher than the result of study conducted in Iran (21.4\%) [16], Kenya(9.9\%) [14], Bangladesh (6.9\%) [18], Pakistan (35\%) [26], EDHS 2016 (36\%) [13] and Northwest Ethiopia (9.2\%)[31]. The possible reason for the variation might be, there were increase client access to the reproductive health related information and the role of LAPM to maintain reproductive organ health or might be an indication that, increased client decision making related to family planning utilization especially LAPM.

The result of this study finding indicates that, $46.2 \%$ and $12.4 \%$ of the study participant utilized contraceptive implant and IUCD respectively. There were variation between the result of this finding and other study result such as study conducted in Iran (14.1\% used IUCD) [16], Kenya (7.9 implant and 0.8 IUCD) [14], Bangladesh (4.6\% implant and $0.6 \%$ IUCD) [18], 2016 EDHS ( $8 \%$ implant, $2 \%$ IUD and $<1 \%$ female sterilization) [13] and Northwest Ethiopia shows (8.2\% Implanol and 1\% IUCD) [31] and Bale-Goba town (IUCD $1.5 \%$, implant $6.5 \%$ ) [5]. The reason for this variation might be due to, increased service provision setting, increased supply and increased trained health care providers. Also those variation may be happened due to different study period.

Partner discussion and approval play role in the selecting and utilizing the contraceptive method of choice. The result of this finding shows that, majority (74.9\%) of the participant ever discussed about any LAPM which is positively associated with demand for LAPM $(\mathrm{AOR}=2.071,95 \%$ $\mathrm{CI}=1.031-4.16)$. The result of this study was lower than the result of study done in the West Ethiopia (81.5\%) and study conducted in northern district of Kenya (79\%) [25, 32]. The possible justification for such discrepancies may be, there were limited involvement of husband in the reproductive health related matters in the study area. Also it might be due that, couple in the study setting has limited knowledge on the importance of joint decision making related to family planning utilization.

\section{Limitation of the Study}

The limitation of this study was cross-sectional nature of the data that temporal relationship between exposure and outcome variable could not be established and also this study do not include health care provider role to meet the demand for LAPM during the service provision session.

\section{Conclusion and Recommendation}

\subsection{Conclusion}

The finding shows that $62.9 \%$ of the participant had demand for LAPM. Factor which are associated with demand for LAPM were ever use of LAPM, couple discussion about LAPM, awareness about LAM and know LAPM. The client who comes for family planning services had expressed demand for LAPM but due to certain reason they like Fear of the contraceptive side effect and misconception related with LAPM hindered married women from utilizing LAPM as contraceptive methods as choice.

\subsection{Recommendation}

From the study result, it can be recommended that:

\subsection{1. $\mathrm{To} \mathrm{MOH}$}

a) Expected to work more to increase working day of the family planning like other health unit (emergency, labor ward...) to avoid/reduce missed opportunity and increase the utilization rate of LAPM.

b) Expected to do more to meet the increase demand over time by motivating the community leaders, religious leaders, husband and give education related to contraceptive misconception and break them so as to increase the acceptance of LAPM by married women like that of short acting contraceptive methods.

\subsubsection{To Assosa Regional Health Bureau}

a) Expected to do more to increase married women awareness related to contraceptive tubal- ligation in the study setting through HEW, media and community education as when to use and how to use the methods and motivate the married women to make tubal-ligation as contraceptive methods of their choice.

b) Expected to do more to increase the involvement of husband on shared decision making and give them education related to the role of family planning to maintain reproductive health at different setting like social meeting area in the community (Idir, conference and the like). 


\subsubsection{To Assossa Governmental Health Institution} Administration

a) Expected to do more to Arrange time and place where short and brief health education related to family planning especially LAPM can be given for those client who come to the institution for family planning, ANC, safe abortion care service and postnatal mother come for vaccine.

b) Assign and continuously follow those health care provider who were assigned to provide health education related to reproductive health mainly LAPM family planning.

c) To do more by assigning health care provider to provide the outreach health education program related to the role of LAPM family planning and counseling's session to the community reproductive women's, husband and any concerned body who play role in the contraceptive utilization.

\subsubsection{To Assosa Governmental Health Institution Midwives/Nurse}

a) Expected to do more too continuously provide counseling related to all contraceptive type and duration of the services, possible side effect and what to do if contraceptive side effect happed and whom to consult to manage the side effect to increase the utilization of LAPM as contraceptive methods of choice.

b) Expected to do more by further probing client reproductive plan and reason for non-utilization LAPM and tell them what's fact about LAPM and try more to reduce misconception/rumors related to contraceptive method of their choice.

c) Work more on the Provision of continuous short and brief health education related to contraceptive method and their role to maintain reproductive health for all client who come for the service, in the community and in the meeting conference of reproductive women.

\subsubsection{To Researchers}

A more intense qualitative and quantitative studies especially in the community settings are needed to gain further insight on acceptance of Long term/acting and permanent methods of family planning by reproductive women, their husband and community religious leaders.

\section{List of Acronyms}

BTL-bilateral tubal ligation

CPR-Contraceptive Prevalence Rate

FP- Family Planning

IUCD- Intra-Uterine Contraceptive Device

LAPM- Long Acting and Permanent Methods

LARC- Long Acting Reversible Contraceptives

MOH- Ministry of Health

RHB- Regional health bureau

SSA- sub-Saharan Africa

TFR- Total Fertility Rate

UN- United Nation

WHO- World Health Organization

\section{References}

[1] UNICEF, WHO, UNESCO, UNFPA, UNDP, UNAIDS, WFP and the World Bank, Facts for Life. vailable at www.factsforlifeglobal.org. 2010; 4th eddition.

[2] MAITETHIA MJ. UTILIZATION OF LONG-TERM AND PERMANENT FAMILY PLANNING METHODS AMONG FAMILY PLANNING CLIENTS AT WESTLANDS HEALTH FACILITIES, NAIROBI COUNTY, KENYA: KENYATTA UNIVERSITY; 2016.

[3] WHO@ Accelerating uptake of voluntary, rights-based family planning in developing countries 2018, avilable at http:/www.who.int.

[4] Family Planning and Population, Division of Reproductive Health, World Health Organization, health benefite of family planning, 1211 Geneva 27, Switzerland.

[5] Takele A, Degu G, Yitayal M. Demand for long acting and permanent methods of contraceptives and factors for non-use among married women of Goba Town, Bale Zone, South East Ethiopia. Reproductive health. 2012; 9: 26.

[6] Ewerling F, Victora CG, Raj A, Coll CVN, Hellwig F, Barros AJD. Demand for family planning satisfied with modern methods among sexually active women in low- and middleincome countries: who is lagging behind? Reproductive health 2018; $15(1): 42$.

[7] Zenebe CB, Adefris M, Yenit MK, Gelaw YA. Factors associated with utilization of long-acting and permanent contraceptive methods among women who have decided not to have more children in Gondar city. BMC women's health. 2017; 17 (1): 75.

[8] United Nations, Department of Economic and Social Affairs, Population Division (2015). Trends in Contraceptive Use Worldwide 2015 (ST/ESA/SER.A/349).

[9] Tibaijuka L, Odongo R, Welikhe E, Mukisa W, Kugonza L, Busingye I, et al. Factors influencing use of long-acting versus short-acting contraceptive methods among reproductive-age women in a resource-limited setting. BMC women's health. 2017; 17 (1): 25 .

[10] Sarah R. Blackstone. Factors Influencing Contraceptive Use in Sub-Saharan Africa: A Systematic Review. International Quarterly of Community Health Education 2017; Vol. 37 (2) 79-9 (DOI: 10.1177/0272684X16685254.

[11] Babalola S, John N. Factors underlying the use of long-acting and permanent family planning methods in Nigeria: a qualitative study. New York: EngenderHealth/The RESPOND Project. 2012.

[12] Yalew SA, Zeleke BM, Teferra AS. Demand for long acting contraceptive methods and associated factors among family planning service users, Northwest Ethiopia: a health facility based cross sectional study. BMC research notes. 2015; 8: 29.

[13] MOH. Central Statistical Agency (CSA) [Ethiopia] and ICF. 2016. Ethiopia Demographic and Health Survey 2016. Addis Ababa, Ethiopia, and Rockville, Maryland, USA: CSA and ICF. 2016. 
[14] Ochako R, Mbondo M, Aloo S, Kaimenyi S, Thompson R, Temmerman $\mathrm{M}$, et al. Barriers to modern contraceptive methods uptake among young women in Kenya: a qualitative study. BMC public health. 2015; 15 (1): 118.

[15] U.S. Agency for International Development (USAID). Facts for Family Planning. Washington, DC: USAID, 2012.

[16] Azmoude E, Behnam H, Barati-Far S, Aradmehr M. Factors Affecting the Use of Long-Acting and Permanent Contraceptive Methods Among Married Women of Reproductive Age in East of Iran. Women's Health Bulletin. 2017; 4 .

[17] Nthusi JN. Factors Associated with Choice of Long Acting Contraceptive Methods among Women of Reproductive Age in Bungoma East Sub-County: Moi University; 2015.

[18] Huda FA, Robertson Y, Chowdhuri S, Sarker BK, Reichenbach L, Somrongthong R. Contraceptive practices among married women of reproductive age in Bangladesh: a review of the evidence. Reproductive health. 2017; 14 (1): 69.

[19] Azmat SK, Ali M, Ishaque M, Mustafa G, Hameed W, Khan $\mathrm{OF}$, et al. Assessing predictors of contraceptive use and demand for family planning services in underserved areas of Punjab province in Pakistan: results of a cross-sectional baseline survey. Reproductive health. 2015; 12 (1): 25.

[20] Bulto GA, Zewdie TA, Beyen TK. Demand for long acting and permanent contraceptive methods and associated factors among married women of reproductive age group in Debre Markos Town, North West Ethiopia. BMC women's health. 2014; 14 (1): 46.

[21] Ouma S, Turyasima M, Acca H, Nabbale F, Obita K, Rama M, et al. Obstacles to family planning use among rural women in Atiak health center IV, Amuru District, northern Uganda. East African medical journal. 2015; 92 (8): 394.

[22] Shabana Anjum PMD, Mahadeo Shinde. Knowledge of Contraceptives Methods and Appraisal of Health Education among Married Woman. International Journal of Science and Research (IJSR). March 2014; Volume 3 Issue 3, www.ijsr.net

[23] Malawi Demographic and Health Survey, National Statistical Office Zomba, Malawi ICF Macro Calverton, Maryland, USA 2010 .

[24] Zomba, Malawi ICF Macro Calverton, Maryland, USA 2010.

[25] Palamuleni ME, Adebowale AS. Women empowerment and the current use of long acting and permanent contraceptive: Evidence from 2010 Malawi Demographic and Health Survey. Malawi Medical Journal. 2014; 26 (3): 63-70.

[26] Tesfalidet Tekelab* ASaDW. Factors Affecting Intention to Use Long Acting and Permanent Contraceptive Methods among Married Women of Reproductive Age Groups in Western Ethiopia: A Community Based Cross Sectional Study. amily Medicine \& Medical Science Research. 2015; Volume 4 (Issue $1 \cdot 1000158$ ).

[27] Azmat SK, Ali M, Ishaque M, Mustafa G, Hameed W, Khan $\mathrm{OF}$, et al. Assessing predictors of contraceptive use and demand for family planning services in underserved areas of Punjab province in Pakistan: results of a cross-sectional baseline survey. Reproductive health. 2015; 12 (1): 25.

[28] Mosha I, Ruben R, Kakoko D. Family planning decisions, perceptions and gender dynamics among couples in Mwanza, Tanzania: a qualitative study. BMC public health. 2013; 13 (1): 523.

[29] Ho LS, Wheeler E. Using program data to improve access to family planning and enhance the method mix in conflictaffected areas of the Democratic Republic of the Congo. Glob Health Sci Pract. 2018; 6 (1): 161-177. https://doi.org/10.9745/GHSP-D-17-00365.

[30] Semere Sileshi Belda1* MTH, Abulie Takele Melku2 and Abdurehaman Kalu Tolol. Modern contraceptive utilization and associated factors among married pastoralist women in Bale eco-region, Bale Zone, South East Ethiopia. BMC health serivce reaserch 2017; 194.

[31] Nieto-Andrade B, Fidel E, Simmons R, Sievers D, Fedorova A, Bell S, et al. Women's Limited Choice and Availability of Modern Contraception at Retail Outlets and Public-Sector Facilities in Luanda, Angola, 2012-2015. Global health, science and practice. $2017 ; 5(1): 75-89$.

[32] Abajobir AA (2014) Intention to use Long-acting and Permanent Family Planning Methods among Married 15-49 years Women in Debremarkos Town, Northwest Ethiopia. Fam Med Med Sci Res 3: 145. doi: 10.4172/23274972.1000145 .

[33] Paul Kisia Malalu, Koskei Alfred, Robert Too, Amon Chirchir. Determinants of Use of Modern Family Planning Methods: A Case of Baringo North District, Kenya. Science Journal of Public Health. Vol. 2, No. 5, 2014, pp. 424-430. doi: 10.11648/j.sjph.20140205.18. 